\title{
О.М. Санду
}

\section{МЕТОД МИФОПОЭТИКИ В ДИЗАЙНЕ}

\begin{abstract}
Рассмотрена мифопоэтика как проектно-исследовательский метод в дизайне, предметом которого является особый тип мифологического сознания и продукты его работы - система представлений о мире, сформированная в виде модели мира. Результатом мифопоэтического проектирования становится целостная осознанная концепция проекта, наполненная ценностно-значимыми культурными смыслами. Анализируется терминологический аппарат метода. Рассмотрены структура и принципь организации модели мира, их роль в формировании проектного замысла, этапь мифопоэтического проектирования.

Ключевые слова: мифопоэтика, метод проектирования, художественно-образная модель мира.
\end{abstract}

\section{Мифопоэтика в гуманитарном знании}

Оживление интереса гуманитарного знания к мифу периодически происходило на протяжении XIX и XX вв. и было обусловлено потребностью формирования целостных представлений о мире. Выделяют стадии развития мировоззрения и соответствующие им виды мышления: донаучные представления (мифологическое, религиозное мышление), научные представления (философское и научное мышление). Особенностью мифологического сознания стало формирование картины мира, которая закладывалась в основу поведения и практической деятельности. Мифологическая картина мира существовала в виде модели и позволяла рассматривать окружающую действительность системно [1].

В каждую эпоху формируется свой тип сознания, однако устойчивое развитие предполагает взаимодействие мифологического и научного сознания, поэтому в современном мировоззрении возникает потребность в воспроизводстве мифологической модели мира как совокупности целостных представлений о мире [2. С. 61-65]. Более характерная для традиционных обществ, она воспроизводилась в контексте романтического и неоромантического искусства XIX-XX вв., а затем в мифопоэтических исследованиях второй половины XX в. Мифопоэтические модели мира реконструировались на основании этнографических сведений, анализа языка и мышления современного человека, хранящего древние представления о мире, а также иррациональной символики из сновидений и художественного творчества.

Термин «мифопоэзия» был предложен направлением литературной критики с целью определения «жанров художественного творчества, тематически или структурно связанных с тем или другим древним мифом» [3. С. 33]. Наиболее развернутое толкование «мифопоэтика» получает в литературе и применяется для изучения не отдельных мифологем, символов или образов, а мифопоэтической модели мира [2. С. 161-166]. В настоящее время под «мифопоэтикой» понимается метод анализа художественного произведения, 
направленный на «исследование «проекции» мифа (мифологического сюжета, образа, мотива и т.д.) на произведение» [4]. Рассматривают подходы различных исследователей к распознаванию мифологических символов, образов и моделей мира, пониманию их значения и роли в художественном творчестве.

По Е.М. Мелетинскому, предметом исследования мифопоэтики становится миф как структура, «которая способна воплотить наиболее фундаментальные черты человеческого мышления и социального поведения» [5. С. 38]. В работе «Историческая поэтика. Литературные эпохи и типы художественного сознания» мифопоэтика представлена характеристикой архаического типа художественного сознания [6. С. 4]. Д.П. Козолупенко разделяет аналитический тип мировосприятия и «мифопоэтический» [7. С. 190]. М.В. Родина подчеркивает универсальность мифопоэтического сознания, определяя его ключевой характеристикой художественного сознания [8]. Н.О. Осипова трактует мифопоэтику как метод, направленный на создание «неомифологических» текстов» «с целью проследить их генезис, развитие и функции в создании целостной картины мира, трансформацию традиционных образов» [9. C. 51-52]. А.А. Татевосян отмечает, что «мифопоэтика предполагает личностное творчество и его исследование посредством анализа мифологических элементов» [10]. Таким образом, в общекультурном смысле мифопоэтика трактуется как методика, направленная на исследование мифологического типа восприятия, мифологической картины мира и понимания своего места в ней.

\section{Сущность метода мифопоэтики в дизайне}

Обращение к мифопоэтике актуализируется в современном дизайне с его доминантой на средовой и информационной сферах проектирования. Интерес к этой теме возник в рамках культурно-экологического подхода в работах К. Кантора, А.В. Иконникова, О.И. Генисаретского, М.С. Кагана, К.А. Кондратьевой и др.

Сущность проектного метода мифопоэтики в дизайне актуализируется в связи с возникшей в современном мировоззрении потребностью в воспроизводстве модели мира. На этапе мифологического сознания практическая деятельность регулировалась путем ритуального воспроизводства модели. В современном мировоззрении регулирующую функцию выполняет культура. В связи с этим задачей мифопоэтического проектирования становится формирование культурно осмысленной концепции проекта. Проведенный в работе [11] анализ позволяет сформулировать мифопоэтику в дизайне как проектно-исследовательский метод, предметом исследования которого является особый тип мифологического сознания (мышления), и продукт его работы система представлений о мире, сформированная в виде модели мира. Результатом мифопоэтического проектирования становится концепция проекта, оформленная в виде модели и наполненная ценностно-значимыми культурными смыслами. Проектный метод мифопоэтики предстает в аспектах:

- познавательном: метод направлен на изучение архаического (мифологического) типа художественного сознания и мышления;

- смыслообразующем: сохранение ценностно-смыслового ядра современной модели мира в виде общекультурных (сверхперсональных) смыслов и обогащение современных мировоззренческих схем универсальными смысла- 
ми и аналогиями путем исторической трансформации общезначимых культурных смыслов;

- ценностно-моделирующем: мифопоэтический метод позволяет формировать ценностно-ориентированное сознание дизайнера и потребителя и воплощать его в дизайн-разработках;

- средовом (экологическом): «превращение» природы в культуру при помощи мифопоэтики происходит без разрушения природы, а путем воспроизводства культурно-значимых символов в синтезе со средой обитания.

\section{Терминологический аппарат метода мифопоэтики}

Первоначально терминология мифопоэтики включала такие понятия, как архетип, архетипический мотив, мифологема, мифема. Архетипическая ветвь мифопоэтики для характеристики смыслового ядра мифов использует набор архетипов - неосознаваемых универсальных «первообразов» и сюжетов, передаваемых из поколения в поколение [12. С. 72-73]. Е.М. Мелетинский применяет понятие «архетипический мотив» как «некий микросюжет, содержащий предикат (действие), агенса, пациенса и несущий более или менее самостоятельный и достаточно глубинный смысл» [13. С. 54]. Архетипы составляют содержание «мифологем» (К. Юнг). Мифологема применяется в ряде значений: синоним архетипа (Т.В. Бовсуновская), минимальная структурная единица мифа (С.Ю. Гуцол) и как конкретное воплощение архетипа (Ю.В. Вишницкая, В.А. Маслова, О.В. Коляда) [14. С. 12]. С.А. Новопашин определяет мифологему в единстве мифологического и логического мышления (миф + логос), как логически обоснованную форму изложения идеи, которую несет в себе миф [15]. Мифологема характеризует специфику современного мышления, рефлексирующего и одновременно оперирующего универсальными общекультурными категориями.

Следующий распространенный в мифопоэтике термин - «мифема». К. Леви-Стросс мифемами называет структурные единицы концентрированного смысла мифа [14. С. 12]. Если мифологема есть «образ обобщѐнный, функционирующий на широком историко-культурном пространстве», то мифема - «более частный образ, который функционирует на меньшем историкокультурном пространстве, чаще в пределах одного художественного произведения» [16. С. 4]. Мифологемы и мифемы раскрывают суть метода мифопоэтики, выполняя функцию знаков-заместителей ситуаций и сюжетов. Мифологемы являются семантическими узлами модели мира.

Вторая группа терминов, которая определяет сущность метода мифопоэтики, сложилась в философии и культурологии. Именно в этих областях возможно обоснование мифопоэтики как способа формирования целостного сознания субъекта культуры. Связь мифопоэтических моделей мира с сознанием и мышлением определяется при помощи ряда понятий: концепт, общезначимые культурные смыслы, культурный код, образ-инвариант мышления, хронотоп.

Для характеристики сознания в российской лингвистике с начала 90-х гг. $\mathrm{XX}$ в. активно употребляется термин «концепт». В.И. Карасик и Г.Г. Слышкин определяют концепт ментальной единицей, используемой для комплексного изучения сознания и культуры, при этом «сознание - область пребывания концепта», а «культура детерминирует концепт» [17. С. 76]. В настоящее 
время исследователи сводят когнитивный статус концепта к его функции быть носителем и одновременно способом передачи смысла, к возможности хранить знание о мире, помогая обработке субъективного опыта [18].

Концепт в мифопоэтике не сводится к созданию только субъективного жизненного опыта, а состоит в сохранении и воспроизводстве общезначимых культурных смыслов, играющих значительную роль в формировании осознанных представлений о мире. Под «культурными смыслами» понимают «выработанную историческим опытом информацию, посредством которой определенное сообщество людей, создающих свой способ бытия, образ жизни, культуру, постигает и понимает окружающий мир и свое предназначение в нем... Смыслы выступают как бытийные константы мира, благодаря чему они становятся основаниями конкретных актов мироотношения» [19].

Общезначимые культурные смыслы, являясь универсальным смысловым зерном коллективной и индивидуальной моделей мира, традиционно воспроизводятся в образной форме. Общеизвестно, что архаическое сознание «мыслит» мифопоэтическими образами пространственно-чувственного восприятия. С их помощью в традиционном обществе кодировались и сохранялись для воспроизводства общекультурные смыслы, представления об устройстве мира (космология), его рождении и развитии (космогония). Образы предстают в качестве структурных элементов модели мира, с помощью которых осуществлялась трансляция смыслов, предметной среде придавалась содержательность. Особая ценность мифопоэтических традиционных образов состоит в их устойчивости. Именно это их свойство позволяло кодировать информацию в виде образов-инвариантов мылиления.

Следующий термин, характеризующий мифопоэтику, - «хронотоп». М.М. Бахтин определял «хронотоп» как форму «ощущения времени и определенное отношение его к пространственному миру» в архаических и традиционных обществах [20. С. 355]. Позднее хронотоп становится характеристикой мифопоэтической модели мира и мифологического типа мышления, в которых наблюдается синкретизм пространства и времени.

Применение мифопоэтики в дизайне как метода формирования осмысленного проектного замысла предполагает, помимо уже известного перечня мифопоэтических, философских и культурологических терминов, использование следующих специфических понятий: аксиоматическое состояние сознания, художественно-образные инварианты, пространственно-временной контекст проекта, художественные мифологемы, художественно-образная модель мира.

Проектный замысел в дизайне предстает как многослойная структура, в которой выделяются «устойчивое смысловое ядро» и периферийные значения объектов. Содержание смыслового ядра в дизайне принято связывать с концепцией проекта. Концепт выражает главный смысл и «опредмечивается» в вещах средствами дизайна. При этом концепт, характеризуя осмысленное содержание, редко ассоциируется с общезначимыми культурными смыслами, чаще выражая авторскую позицию. Между тем исследователи сознания утверждают тот факт, что устойчивость смысловому ядру придают «универсальные культурные смыслы», генерация которых осуществляется на надындивидуальном уровне. Смысловое ядро проектного замысла также формируется на основе общезначимых культурных смыслов. При этом необходимо 
понимать, что осмысление культурологического содержания требует особого способа воспроизводства на уровне индивидуального сознания. Этот процесс осуществляется при помощи аксиоматических состояний.

М.К. Мамардашвили отмечал, что без «аксиоматических качеств сознания» невозможно понимание мира, а «психологическая жизнь представляет собой хаос, распадается» [21. С. 59]. По О.И. Генисаретскому, «аксиоматические состояния сознания» принадлежат высшему уровню творческого самосознания художника, в них сходятся: выработанная художником творческая концепция, ценностные истоки творчества, приверженность избранному образу жизни и мысли [22]. В искусствознании и эстетике именно посредством мифологических концепций «символизируются феномены аксиоматического опыта», которые изначально неосознанны и становятся доступными индивидуальному сознанию благодаря работе воображения при взаимодействии с родовым преданием и родовой средой [23].

Воспроизводство (визуализация) смысловых аксиом в дизайне осуществляется в художественно-образной форме. Аксиомы сосредоточены в мифопоэтических художественно-образных инвариантах, универсальность которых позволяет им оставаться актуальными в информационную эпоху и воплощаться в современных дизайн-концепциях. Именно в образах сохраняется основная смысловая канва. Анализ мифологических текстов и базовых мифопоэтических моделей мира [24-26] позволяет выделить систему эмоционально окрашенных мифопоэтических художественных образов-инвариантов: природные (стихии, астральные, географические объекты, растительные, зооморфные, ландшафтные и т.п.), антропоморфные (соматические, гендерные), социальные, сакральные, предметные, пространственные или структурные (центр или точка отсчета пространства, граница, стороны света, горизонталь, вертикаль, перекресток, уровни, «священные места» и т.п.) и временные или динамические («правремя» или время первотворения, образы цүиклического времени и пути, «священные дни»).

Художественные мифологемы и мифемы являются узлами модели мира. Значение мифологем для дизайнерского проектирования в качестве моделей средового поведения, связанных с бессознательными реакциями, определяет И.А. Розенсон: мифологемы есть «структурные единицы сюжетного хода», обладающие «чрезвычайно сильным эмоциональным потенциалом», могут быть использованы в качестве «выразительных средств формирования предметно-пространственной среды» [27. С. 112].

Для формирования «периферии» проектного замысла особое значение приобретает пространственно-временной контекст дизайн-концепции. Пространственный контекст складывается по аналогии с процессом осмысления региональных особенностей территории обитания в мифологическом мышлении. Мифологические представления о пространстве были созданы культурой, но при этом оставались связанными с природным окружением. Как отмечает Д.Н. Замятин, «образы пространства... Их проективное наложение на пространство рождает уникальную мифологию местности, «дух местности» [28]. Мифологические «образы пространства» возникали в регулярных контактах наблюдателя с природным окружением, закреплялись в процессе деятельности по освоению природы при помощи моторной памяти и существовали в сознании в виде визуальных стереотипов. Они становятся визуальным 
«кодом местности» и источником смысла, который отражался в предметной рукотворной среде, окружающей человека. По аналогии с пространственными образами в каждую эпоху бытуют временныле (динамические) инварианты «образы времени». Они определяют исторический временно́й контекст проектного замысла, который может быть выявлен на пересечении традиционного и инновационного. В настоящее время приходит понимание необходимости воспроизводства традиционных «инвариантов-образов времени» и их трансляции в современном мышлении.

Таким образом, в соответствии с методикой мифопоэтики в дизайне, устойчивое смысловое ядро творческого проектного замысла формируется на основе общезначимых культурных смыслов-аксиом, которые постигаются посредством аксиоматических состояний индивидуального сознания и выражаются в виде ценностных ориентаций потребителя. Периферия проектного замысла создается в контексте пространственно-временной ситуации при помощи образов-инвариантов пространства и времени.

\section{Структура и принципы организации мифологической модели мира}

В дизайне в процессе формирования концепции проекта результатом работы художественного сознания и дизайн-мышления становится художественно-образная модель мира как упорядоченная система, композиционная целостность. Смысловыми единицами в дизайн-концепции являются общекультурные смыслы (надындивидуальный уровень) и аксиоматические состояния (индивидуальный уровень). Структурные элементы модели мира художественные образы-инварианты, обладающие свойствами хронотопичности, устойчивости. Узлами модели мира являются художественные мифологемы и мифемы. Периферия проектного замысла складывается при помощи пространственно-временного контекста. Образы и мифологемы организуются в блоки при помощи принципов организации модели мира.

Как отмечает Д.П. Козолупенко, человек с мифопоэтическим типом мировосприятия «находит себя» в мире (познание мира является основанием для идентификации) [29. С. 12]. В связи с этим можно добавить, что для мифопоэтического сознания божественный, природный и общественный «порядок мира» первичен над индивидуальными представлениями о нем. Именно такая специфика мышления позволяет сформировать содержательный блок модели мира в соответствии с принщипами сакральным, природной и соцчиальной обусловленности.

Еще М. Элиаде определял сакральный характер мифологического сознания. Сакрализация в сознании традиционного человека состояла в переносе атрибутов «священного порядка» мира богов на объекты «профанного» предметного мира. В процессе сакрализации осуществлялась эмоциональная настройка на место обитания, которая формировала своеобразное ценностное отношение человека к объектам предметного мира. Зависимость родового коллектива в эпоху традиционного общества от территории жизни формировала «природный порядок» земного существования. Эта особенность выражается в первичности природного над индивидуальным в мировоззрении традиционного человека, что находит отражение в принципе природной обусловленности. Принщип социальной обусловленности определяет первичность 
общественного над индивидуальным. В модели мира этот принцип поддержан набором сочииальных образов-инвариантов, при помощи которых задается «человеческий порядок» традиционного образа жизни.

Мифопоэтическая модель мира организуется при помощи композициионных принцииов формообразования - статических (пространственных) и динамических (временных). Они позволяют организовать отдельные структурные элементы в пространственно-временной блок модели. Пространственные принципы организации - доминанты, оппозиции. Принции доминанты задает центр пространства-времени традиционного мировоззрения, который выполняет роль аттрактора, ориентира пространственной иерархии. М. Элиаде выделяет «Центр Мира» как «точку отсчета» пространства и времени в мифопоэтическом сознании [30. С. 24]. В качестве пространственного центра мифологической модели мира выделяется обжитое пространство, мир людей. Эталоном для него часто становится сакральный образ - содержательная доминанта, центр содержательного блока модели мира. Пространственный и содержательный центры не всегда совпадают. Для мифологического мировоззрения «небесный» порядок ставится выше «природного» и «социального», поэтому сакральный образ является доминатным по отношению к природным и социальным образам. Помимо содержательного и пространственного центров существуют и другие образы, которые также фиксируют «сакральные зоны» пространства.

Мировоззренческими оппозициями можно назвать типы линейных связей между узлами-образами, выражающимися в их противопоставлении по отношению друг к другу. Принции оппозищий формирует пространство модели мира в трех измерениях. Противопоставление «верхнего» и «срединного» мира, середины и «нижнего» мира создают вертикальный срез модели мира. Оппозиции центра и сторон света дают возможность модели расти в горизонтальной плоскости. Вертикальное и горизонтальное измерения складываются в объемную модель мира.

Динамические связи между мифологическими образами времени выражены при помощи принципа развития. Как отмечает В.Н. Топоров, мифологические космогонии насыщены сюжетами о происхождении природных стихий, об отделении неба от земли, о появлении земной тверди из мирового океана и светил на небе или о создании ландшафта, растений, животных и человека [2. С. 163]. Все эти процессы так или иначе отражают динамический принцип развития мира, который в мифологическом сознании описывается оппозицией «рождение - смерть» и задает направление трансформаций (рост или деградация).

Особенностью мифопоэтического сознания является представление о мире как совокупности взаимодействующих живых существ. Мифопоэтика строится на борьбе Хаоса и Космоса и исследует упорядоченность, которая присутствует в устройстве мира, законы его возникновения и существования. В мифах мировой порядок достигался при помощи равновесия со средой, между людьми внутри социума, с богом. В соответствии с принцииом системности (целостности) составные части мифологической модели мира уравновешены и объединены в единое целое.

Доминантно-аналитический тип мировосприятия (по Д.П. Козолупенко), характерный для современного сознания, определяет «знание о себе данным 
до знания о мире», т.е. идентификация человека предшествует познанию мира [7. С. 12]. В связи с этим ценность мифологической модели мира сохраняется, но трансформируется. В дизайне на этапе разработки концепции дизайн-проекта актуальным остается формирование целостной модели мира. В соответствии с методикой мифопоэтики, проектный замысел формируется на основе принципов смыслообразования (сакральности, природной и социальной обусловленности) и принципов формообразования (пространственных и динамических).

Смыслообразующие принщипь продолжают участвовать в создании содержательного ядра (блока) современной модели мира, но «пропускаются» через ценностный фильтр. Принщип сакрализащии в дизайне предполагает наделение проектного замысла общезначимыми культурными смыслами, которые в отличие от «божественных» смыслов мифологического сознания являются ценностно-значимыми для дизайнера и потребителя. Мифопоэтический метод проектирования также определяет приниип природной (экологической) обусловленности проектного замысла. Ценность «природного порядка» в концепции дизайн-объекта находит выражение в значимости природных образов для дизайн-концепции. Мифопоэтический принции сощииокультурной обусловленности проектного замысла особенно актуален в связи со средовым и индивидуализированным подходами к проектированию. Пространственно-временной контекст проектного замысла складывается при помощи принципов организации пространства и времени. Композиционные принципы - доминанты, оппозиций - вместе с принциипом развития в дизайн-концепции способствуют формированию структуры и драматургии проекта.

Принции системности направлен на гармонизацию структурных взаимосвязей. Его сущность заключается в том, что при создании проекта дизайнер выстраивает собственную картину мира, в которой отдельные представления объединены в систему. В современном мировоззрении системность достигается при помощи динамического равновесия, когда элементы мифологического сознания синхронистически сочетаются с общезначимыми культурными смыслами. При этом осуществляется не копирование мифологических идей, а осмысленное воспроизводство устойчивых традиционных смыслов в проектном замысле.

Таким образом, структура художественно-образной модели мира составлена из блоков: содержательного и пространственно-временно́го. Ее элементами являются мифопоэтические образы-инварианты: сакральный, природные, социальные, пространственные (статические), временны́е (динамические). Смыслообразующие принципы - сакральный, социальной и природной обусловленности; формообразующие - композиционные (доминанты оппозиций), динамический; гармонизирующий - принцип системности.

\section{Этапы мифопоэтического проектирования}

Методика мифопоэтики предполагает некую последовательность проектирования, которая может быть описана при помощи ряда последовательных этапов: коллективная культурная память $\rightarrow$ активное распознавание культурных смыслов $\rightarrow$ «вживление» общезначимых культурных смыслов в индивидуальную картину мира дизайнера (потребителя) $\rightarrow$ визуализация образов- 
инвариантов в объектах проекта (мифологемах) $\rightarrow$ проектный замысел $\rightarrow$ новый культурный артефакт. Указанные этапы требуют разъяснения.

Первоначально дизайнер имеет дело с объектами культурного наследия, частью коллективного сознания («банка памяти») традиционной культуры, хранящего в себе многообразие культурных смыслов. Основу коллективной памяти составляют образы мира, с помощью которых кодируется информация об устройстве мира. Смыслы хранятся в образах в «свернутом» виде, поэтому их содержание недоступно при беглом знакомстве с образами. Для воспроизводства необходима расшифровка (активное распознавание) культурных смыслов, которая предполагает определение их значения и трансформацию в проектные смыслы. Активное распознавание мифологических образов происходит по аналогии с сакрализацией объекта в мифологическом сознании: в процессе когнитивного знакомства с мифологическими текстами. При этом расшифровка значения мифологических символов происходит с учетом контекста. В процессе когнитивного распознавания культурные смыслы «разворачиваются», индивидуальная картина мира обогащается культурными смыслами, происходит «вживление» их в сознание человека.

Далее осуществляется художественно-образное выражение проектных смыслов, визуализация культурных смыслов в отдельных мотивах-мифологемах проекта. Из отдельных мифологем (объектов проекта) выстраивается система проекта в соответствии с мифопоэтическими принципами организации проектного замысла. Сборка мифологем в модель мира происходит по схеме: модель мира (проектный замысел) = образ-инвариант (носитель общезначимых культурных смыслов) + образ пространства (привязка к месту по природному принципу) + образ времени (привязка в соответствии с нормами времени) + социальный образ (привязка к культурной общности). В результате создается целостный дизайн-объект, в котором универсальное смысловое ядро сочетается с вариативной периферией. Спроектированный таким образом дизайн-объект становится новым артефактом, который упорядочивает картину мира и включается в ценностный мир субъектов культуры.

\section{Вывод}

Метод мифопоэтического проектирования решает вопросы синтеза в проектном замысле традиционного и инновационного, природного и культурного, универсального и индивидуального, общезначимых культурных и индивидуальных смыслов и ценностных ориентаций в смыслообразовательной плоскости. В этом случае синтез традиционного и инновационного, восстановление и гармонизация природной и культурной сред осуществляется на уровне трансляции общезначимых культурных смыслов путем их воспроизводства и включения в проектный замысел. Традиционные представления преобразовываются в общезначимые культурные смыслы, которые формируют в сознании потребителя устойчивые ценностные ориентации. Интерес к материальной культуре традиционного общества воплощается не путем формального копирования образцов, а в ходе создания осмысленных дизайнпродуктов, адаптированных под запросы конкретного регионального потребителя. Традиционная символика, технологические и конструктивные приемы воплощаются в современных художественных, функциональных, конструктивных и технологических решениях не единично, а в комплексных 
средовых объектах. В связи с этим методика мифопоэтического проектирования предлагается автором в качестве образовательной методики для программ художественно-промышленной и архитектурно-дизайнерской направленности в вузах $[31,32]$.

\section{Литература}

1. Санду О.М. Построение художественно-образной модели мира с использованием хронотопических инвариантов мышления // Исторические, философские, политические и юридические науки, культурология и искусствоведение. Вопросы теории и практики. 2017. № 3-1 (77). C. $129-131$.

2. Мифы народов мира. Энциклопедия: в 2 т. Т. 2: К-Я / гл. ред. С.А. Токарев. М. : Советская энциклопедия, $1992.719 \mathrm{c}$.

3. Токарева Г.А. Мифопоэтика У. Блейка. Петропавловск-Камчатский : Изд-во КамГУ, 2006. $350 \mathrm{c}$.

4. Белокурова С.П. Словарь литературоведческих терминов. СПб. : Паритет, 2006.314 с.

5. Мелетинский Е.М. Поэтика мифа. М. : Наука, 1976. 407 с.

6. Историческая поэтика. Литературные эпохи и типы художественного сознания / под ред. П.А. Гринцер. М. : Наследие, 1994. 512 с.

7. Козолупенко Д.П. Анализ мифопоэтического мировосприятия // Эпистемология и философия науки. 2009. № 2 (20). С. 190-197.

8. Родина М.В. Миф и его поэтика в цикле К.С. Льюиса «Хроники Нарнии»: проблема художественной функциональности: дис. ... канд. филол. наук. Тамбов, 2015. 265 с.

9. Осипова Н.О. Мифопоэтика как сфера поэтики и метод исследования // Социальные и гуманитарные науки. Отечественная и зарубежная литература. 2000. № 3. С. 46-52.

10. Татевосян A.A. Учебно-методический комплекс по дисциплине «Теоретическая и прикладная мифопоэтика». URL: http://doc.knigi-x.ru/22raznoe/50982-1-sostavlen-sootvetstvii-dayugosudarstvennimi-trebovaniyami-soderzhaniya-urovnyu-direktor-instituta.php (дата обращения: 19.05.2018).

11. Санду О.М. Сущность мифопоэтики в дизайне. Этапы мифопоэтического проектирования // Декоративное искусство и предметно-пространственная среда. Вестник МГХПА. 2018. № 3. С. $143-151$.

12. Энциклопедия эпистемологии и философии науки / под ред. И.Т. Красавина. М., 2009. $1248 \mathrm{c}$.

13. Мелетинский Е.М. О литературных архетипах. М., 1994. 136 с.

14. Круталевич А.Н. «Мифологема» в понятийном аппарате культурологии // Культура и цивилизация. 2016. № 1. С. 10-21.

15. Новопашин C.A. Мифологемы как технология продвижения территорий. От мифа к мифологеме. URL: http://www.bkworld.ru/archive/y2008/n06-2008/Mifologemy_kak_tehnologija _prodvizhenija_territorijj_Ot_mifa_k_mifologeme.html (дата обращения: 12.02.2018).

16. Ращевская Е.П. Космогонический миф Даниила Андреева и культура Серебряного века: автореф. дис. ... канд. культурологии. Киров, 2006. 17 с.

17. Карасик В.И., Слышикин Г.Г. Лингвокультурный концепт как единица исследования // Методологические проблемы когнитивной лингвистики: сб. науч. тр. Воронеж, 2001. С. 75-80.

18. Ковлакас Е.Ф. Концепт «Гора» как образ «Духовного ориентира» народа (на примере оронимов Кубани и Северного Кавказа) // Вестник Адыгейского государственного университета. Серия 2: Филология и искусствоведение. 2008. № 6. URL: https://cyberleninka.ru/article/n/kontsept-gora-kak-obraz-duhovnogo-orientira-naroda-na-primere-oronimov-kubani-isevernogo-kavkaza (дата обращения: 14.02.2018).

19. Смысль культурные URL: http://www.artap.ru/cult/smsl.htm (дата обращения: 28.05.2017).

20. Бахтин М.М. Эстетика словесного творчества. М. : Искусство, 1979. 424 с.

21. Мамардашвили М.К. Классический и неклассический идеалы рациональности. Тбилиси : Мацниереба, 1984. 82 с.

22. Генисаретский О.И. Искусство и духовная жизнь. URL: http://prometa.ru/olegen/publications/133/\#_Тос95099430 (дата обращения: 28.03.2018).

23. Генисаретский О.И. Внемля себе. О человеке в зеркале мифологической традиции. URL: http://www.intelros.ru/readroom/orientiry-metafizicheskie-issledovaniya-cheloveka/vyp-4- 
2007/7863-vnemlya-sebe-o-cheloveke-v-zerkale-mifologicheskoj-tradicii.html (дата обращения: 28.03.2018).

24. Санду О. М. Вариации образа мира «чаша» в традиционном искусстве народов Средиземноморья // Декоративное искусство и предметно-пространственная среда. Вестник МГХПА. 2017. № 3. С. 33-45.

25. Санду О.М. Система образов-инвариантов мифопоэтической модели мира «гора» в искусстве горцев // Архетип и универсалии в искусстве христианского мира от античности до современности: изобразительное и монументально-декоративное искусство, архитектура и предметно-пространственная среда: материалы научной конференции. XXVI Международные Рождественские образовательные чтения: «Нравственные ценности и будущее человечества». M., 2018. C. 80-86.

26. Санду O.M. Статические и динамические принципы организации художественнообразной модели мира «колесо» кочевых народов Центральной Азии и Сибири // Декоративное искусство и предметно-пространственная среда. Вестник МГХПА. 2018. Т. 2, № 1. С. 59-69.

27. Розенсон И.А. Основы теории дизайна: учебник для вузов. 2-е изд. СПб., 2013. 256 с.

28. Замятин Д.Н. Культура и пространство. Моделирование географических образов. М. : Знак, 2006. $488 \mathrm{c}$.

29. Козолупенко Д.П. Мифопоэтическое мировосприятие и миф: принципы взаимодействия и проявления в культуре // Вопросы культурологии. 2009. № 6. С. 12-16.

30. Элиаде М. Священное и мирское / пер. с фр. Н.К. Гарбовского. М., 1994. 144 с.

31. Санду О.М. Мифопоэтика скандинавского дизайна. Ижевск, 2017. 140 с.

32. Санду O.M. Мифопоэтика скандинавской и финской региональной архитектуры рубежа XIX-XX веков // Архитектура и строительство России. 2017. № 2 (222). С. 112-115.

Olga M. Sandu, Izhevsk State Technical University named after M.T. Kalashnikov (Izhevsk, Russian Federation).

E-mail: sanduolgamail@gmail.com

Vestnik Tomskogo gosudarstvennogo universiteta. Kul'turologiya i iskusstvovedeniye - Tomsk State University Journal of Cultural Studies and Art History, 2020, 39, pp. 117-129.

DOI: $10.17223 / 2220836 / 39 / 11$

THE METHOD OF MYTHOPOETICS IN DESIGN

Keywords: the mythopoetics; the design method; the artistic-imaginative model of the world.

The appeal to mythopoetics is emerging in modern design with the focus on its environmental and information spheres. The analysis of literature leads to considering mythopoetics as a design and research method, whose subject is a specific type of mythological consciousness and the product of its work - the system of ideas about the world, formed into a model. Mythopoetics appears in cognitive, sense-forming, value-modeling and environmental aspects.

The essence of mythopoetic design is becoming more relevant in the modern worldview due to the need for reproducing the world model. At the stage of mythological consciousness, practical activity was regulated by ritual reproduction of the model. In the modern worldview, the regulating function is performed by culture. Therefore, the task of mythopoetic design is to form a concept of a project filled with value cultural meanings.

The basic terms of mythopoetics include traditionally used concepts (an archetype, a mythologeme, a mytheme), philosophical and cultural terms (a concept, a cultural meanings, an imaginative invariant of thinking, a chronotope), and specific concepts (axiomatic state of individual consciousness, artistic and imaginative invariants, a spatiotemporal context of a project, an artistic and imaginative model of the world). In design, the result of work of artistic consciousness and design thinking is the concept of a project shaped into the artistic and imaginative model of the world.

The semantic core of the design concept is based on cultural meanings and axioms, which are comprehended by means of axiomatic state of individual consciousness and expressed as consumer's value orientations. The periphery of the design concept is formed by the spatial and time context of project.

The artistic and imaginative model of the world appears as a compositional integrity consisting of structural elements, i.e. artistic and imaginative invariants. The conducted analysis of mythopoetic models of the world yields a system of artistic and imaginative invariants, includingnatural, anthropomorphic, social, sacred, objective, spatial, and dynamic. The structural elements of the model are organized into blocks using the principles of organization. The principles of semantic organization are 
applied in the creation of a semantic block. The spatiotemporal context of the design concept is formed by the principles of space and time organization.

The method of mythopoetics presupposes the sequence of design stages: recognition of cultural meanings, their "implantation" into the individual worldview, and visualization of artistic and imaginative invariants in design objects. The method of mythopoetic design solves the task of synthesis of traditional and innovative aspects, natural and cultural aspects, universal cultural and individual meanings, and value orientations in the design concept.

\section{References}

1. Sandu, O.M. (2017) Developing an artistic imaginative world model using chronotopic invariants of thinking. Istoricheskie, filosofskie, politicheskie i yuridiche-skie nauki, kul'turologiya i ikusstvovedenie. Voprosy teorii i praktiki - Historical, Philosophical, Political and Law Sciences, Culturology and Study of Art. Issues of Theory and Practice. 3-1(77). pp. 129-131. (In Russian).

2. Tokarev, S.A. (ed.) (1992) Mify narodov mira. Entsiklopediya: $v 2 t$. [Myths of the peoples of the world. Encyclopedia: in 2 volumes]. Vol. 2. Moscow: Sovetskaya entsiklopediya.

3. Tokareva, G.A. (2006) Mifopoetika U. Bleyka [Mythopoetics by W. Blake]. PetropavlovskKamchatskiy: Kamchatka State University.

4. Belokurova, S.P. (2006) Slovar' literaturovedcheskikh terminov [Dictionary of Literary Terms]. St. Petersburg: Paritet.

5. Meletinsky, E.M. (1976) Poetika mifa [The poetics of myth]. Moscow: Nauka.

6. Grintser, P.A. (1994) Istoricheskaya poetika. Literaturnye epokhi i tipy khudozhestvennogo soznaniya [Historical poetics. Literary epochs and types of artistic consciousness]. Moscow: Nasledie.

7. Kozolupenko, D.P. (2009) Analiz mifopoeticheskogo mirovospriyatiya [An analysis of mythopoetic worldview]. Epistemologiya i filosofiya nauki-Epistemology and Philosophy of Science. 2(20). pp. 190-197.

8. Rodina, M.V. (2015) Mif i ego poetika v tsikle K.S. L'yuisa "Khroniki Narnii”: problema khudozhestvennoy funktsional'nosti [Myth and its poetics in K.S. Lewis's "The Chronicles of Narnia": the problem of artistic functionality]. Philology Cand. Diss. Tambov.

9. Osipova, N.O. (2000) Mifopoetika kak sfera poetiki i metod issledovaniya [Mythopoetics as a sphere of poetics and research method]. Sotsial'nye $i$ gumanitarnye nauki. Otechestvennaya i zarubezhnaya literatura. 3. pp. 46-52.

10. Tatevosyan, A.A. (n.d.) Uchebno-metodicheskiy kompleks po distsipline "Teoreticheskaya $i$ prikladnaya mifopoetika [Educational-methodical complex for the discipline "Theoretical and Applied Mythopoetic"]. [Online] Available from: http://doc.knigi-x.ru/22raznoe/50982-1-sostavlensootvetstvii-dayu-gosudarstvennimi-trebovaniyami-soderzhaniya-urovnyu-direktor-instituta.php (Accessed: 19th May 2018).

11. Sandu, O.M. (2018) Sushchnost' mifopoetiki v dizayne. Etapy mifopoeticheskogo proektirovaniya [The essence of mythopoetics in design. Stages of mythopoetic design // Decorative art and subject-spatial environment]. Dekorativnoe iskusstvo i predmetno-prostranstvennaya sreda. Vestnik MGKhPA - Decorative Art and environment. Gerald of the MGHPA. 3. pp. 143-151.

12. Krasavin, I.T. (ed.) (2009) Entsiklopediya epistemologii i filosofii nauki [Encyclopedia of Epistemology and Philosophy of Science]. Moscow: Kanon+.

13. Meletinsky, E.M. (1994) O literaturnykh arkhetipakh [About literary archetypes]. Moscow: [s.n.].

14. Krutalevich, A.N. (2016) "Mifologema" v ponyatiynom apparate kul'turologii ["Mythologema" in the conceptual apparatus of cultural studies]. Kul'tura i tsivilizatsiya - Culture and Civilization. 1. pp. $10-21$.

15. Novopashin, S.A. (2008) Mifologemy kak tekhnologiya prodvizheniya territoriy. Ot mifa $k$ mifologeme [Mythologemes as a technology for promoting territories. From myth to mythologeme]. [Online] Available from: http://www.bkworld.ru/archive/y2008/n06-2008/Mifologemy_kak_tehnologija_prodvizhenija_territorijj_Ot_mifa_k_mifologeme.html (Accessed: 12th February 2018).

16. Rashchevskaya, E.P. (2006) Kosmogonicheskiy mif Daniila Andreeva $i$ kul'tura Serebryanogo veka [Cosmogonic myth of Daniil Andreev and the culture of the Silver Age]. Abstract of Culturology Cand. Diss. Kirov.

17. Karasik, V.I. \& Slyshkin, G.G. (2001) Lingvokul'turnyy kontsept kak edinitsa issledova-niya [Linguocultural concept as a unit of research]. In: Sternin, I.A. (ed.) Metodologicheskie problemy kognitivnoy lingvistiki [Methodological problems of cognitive linguistics]. Voronezh: Voronezh State University. pp. $75-80$. 
18. Kovlakas, E.F. (2008) Kontsept "Gora" kak obraz "Dukhovnogo orientira" naroda (na primere oronimov Kubani i Severnogo Kavkaza) [The concept of "mountain" as an image of the people's "Spiritual guide" (a case study of the Kuban and North Caucasus oronims)]. Vestnik Adygeyskogo gosudarstvennogo universite-ta. Seriya 2: Filologiya i iskusstvovedenie. 6. [Online] Available from: https://cyberleninka.ru/ar-ticle/n/kontsept-gora-kak-obraz-duhovnogo-orientira-naroda-na-primereoronimov-kubani-i-severnogo-kavkaza (Accessed: 14th February 2018).

19. Artap.ru. (n.d.) Smysly kul'turnye [Cultural meanings]. [Online] Available from: http://www.artap.ru/cult/smsl.htm (Accessed: 28th May 2017).

20. Bakhtin, M.M. (1979) Estetika slovesnogo tvorchestva [Aesthetics of verbal creativity]. Moscow: Iskusstvo.

21. Mamardashvili, M.K. (1984) Klassicheskiy i neklassicheskiy idealy ratsional'nosti [Classical and non-classical ideals of rationality]. Tbilisi: Matsniereba.

22. Genisaretsky, O.I. (n.d.) Iskusstvo i dukhovnaya zhizn' [Art and Spiritual Life]. [Online] Available from: http://prometa.ru/olegen/publica $\neg$ tions/133/\#_Toc95099430 (Accessed: 28th March 2018).

23. Genisaretsky, O.I. (n.d.) Vnemlya sebe. O cheloveke v zerkale mifologicheskoy traditsii [Listen to yourself. About a man in the mirror of mythological tradition]. [Online] Available from: http://www.intelros.ru/readroom/orientiry-metafizicheskie-issledovaniya-cheloveka/vyp-4-2007/7863vnemlya-sebe-o-cheloveke-v-zerkale-mifologicheskoj-tradicii.html (Accessed: 28th March 2018).

24. Sandu, O.M. (2017) Variatsii obraza mira "chasha" v traditsionnom iskusstve narodov Sredizemnomor'ya [Variations of the image of the world "bowl" in the traditional art of the Mediterranian peoples]. Dekorativnoe iskusstvo i predmetno-prostranstvennaya sreda. Vestnik MGKhPA - Decorative Art and environment. Gerald of the MGHPA. 3. pp. 33-45.

25. Sandu, O.M. (2018) [The system of images-invariants of the mythopoetic model of the world "mountain" in the art of the highlanders]. Arkhetip $i$ universalii $v$ iskusstve khristianskogo mira ot antichnosti do sovremennosti: izobrazitel'noe i monumental'no-dekorativnoe iskusstvo, arkhitektura i predmetno-prostranstvennaya sreda [Archetype and universals in the art of the Christian world from antiquity to the present: fine and monumental decorative art, architecture and subject-spatial environment]. Proc. of the 26th Conference. Moscow. pp. 80-86. (In Russian).

26. Sandu, O.M. (2018) Staticheskie i dinamicheskie printsipy organizatsii khudozhestvennoobraznoy modeli mira "koleso" kochevykh narodov Tsentral'noy Azii i Sibiri [Static and dynamic principles of organization of the artistic-figurative model of the world "wheel" of the nomadic peoples in Central Asia and Siberia]. Dekorativnoe iskusstvo i predmetno-prostranstvennaya sreda. Vestnik MGKhPA - Decorative Art and environment. Gerald of the MGHPA. 2(1). pp. 59-69.

27. Rozenson, I.A. (2013) Osnovy teorii dizayna [Basics of design theory]. St. Petersburg: Piter.

28. Zamyatin, D.N. (2006) Kul'tura i prostranstvo. Modelirovanie geograficheskikh obrazov [Culture and space. Modeling geographic images]. Moscow: Znak.

29. Kozolupenko, D.P. (2009) Mifopoeticheskoe mirovospriyatie i mif: printsipy vzaimodeystviya i proyavleniya $\mathrm{v}$ kul'ture [Mythopoetic worldview and myth: principles of interaction and manifestation in culture]. Voprosy kul'turologii. 6. pp. 12-16.

30. Eliade, M. (1994) Svyashchennoe i mirskoe [Sacred and Secular]. Translated from French by N.K. Garbovsky. Moscow: Moscow State University.

31. Sandu, O.M. (2017) Mifopoetika skandinavskogo dizayna [Mythopoetics of Scandinavian design]. Izhevsk: [s.n.].

32. Sandu, O.M. (2017) Mythopoetics of the Scandinavian and Finnish regional architecture at the turn of the 19th - 20th centuries. Arkhitektura i stroitel'stvo Rossii - Architecture and Construction of Russia. 2(222). pp. 112-115. (In Russian). 